\title{
La capacidad jurídica de las personas con discapacidad en Colombia y los nuevos retos normativos
}

The legal capacity of people with disabilities in Colombia and the new regulatory challenges

Geovana Andrea Vallejo Jiménez ${ }^{1 \otimes}$

Mónica Isabel Hernández Ríos ${ }^{2} \otimes$

Adriana Elvira Posso Ramírez

Fecha correspondencia:

Recibido: septiembre 12 de 2016

Revisión: diciembre 6 de 2016.

Aceptado: diciembre 13 de 2016.

\section{Forma de citar:}

Vallejo Jiménez, G.A. Hernández Ríos, M.i.,

\& Posso Ramírez, A.E. (2017). La capacidad

jurídica de las personas con discapacidad en

Colombia y los nuevos retos normativos. Rev.

CES Derecho., 8(1), 3-21.

Open access

Términos de uso

Licencia creative commons

Ética de publicaciones

Revisión por pares

Gestión por Open Journal System

DOI: http://dx.doi.org/10.21615/cesder.8.1.1

ISSN: 2145-7719

Sobre el artículo:

Este artículo es producto de los resultados

parciales y originales obtenidos en el proyecto

de investigación titulado: "La capacidad

jurídica a la luz de la Convención de Derechos

Humanos de las personas con discapacidad

en los procesos civil, familia, laboral y penal

en Colombia" adelantado por los grupos de

investigación "Derecho, cultura y ciudad" de

la Universidad San Buenaventura (Seccional

Medellín), "Proceso penal y Delito" de la

Universidad Autónoma Latinoamericana

-UNAULA- y "Derecho y poder" de la

\section{Comparte}

\section{Resumen}

Este artículo pretende analizar los retos normativos que tiene para Colombia la aplicación de la Convención sobre los Derechos de las Personas con Discapacidad en materia civil, de familia, penal, laboral y seguridad social. En este texto se expondrán los diferentes desafíos jurídicos que actualmente deberá afrontar el estado colombiano para asumir los compromisos adquiridos con la firma y ratificación de la Convención, especialmente con la generación de las garantías legales, políticas institucionales y cambios de mentalidad en los operadores jurídicos, para lograr el reconocimiento de la capacidad jurídica de las personas con discapacidad.

Palabras clave: Capacidad jurídica, personas con discapacidad, acceso a la justicia, igualdad, proceso judicial.

\section{Abstract}

This article will analyze the normative challenge that Colombia has with signature of the Convention on the Rights of Persons with Disabilities on the subject as civil law, family law, criminal law, labor law and social security. This document explain it about different challenges the state Colombian to assume the commitments made with the signature and ratification especially with the generation of the legal guarantees; institutional policy and some changes of thinking in the legal professionals for recognize the rights about the legal capacity of people with disabilities.

Keyword: Legal capacity, people with disabilities, access to justice, equality, judicial process.

\section{Introducción}

Este artículo es producto del avance del proyecto de investigación "La capacidad jurídica a la luz de la Convención de Derechos Humanos de las personas con discapacidad en los procesos civil, familia, laboral y penal en Colombia" que se adelanta conjuntamente entre los grupos de investigación Derecho, cultura y ciudad de la Universidad San Buenaventura (seccional Medellín), Proceso penal y delito de la Universidad Autónoma Latinoamericana, Derecho y poder de la Universidad Eafit y la Corporación Discapacidad Colombia. La investigación que se viene adelantando tiene una metodología de tipo cualitativo, cuyo desarrollo viene siguiendo la propuesta de Galeano (2003), la ruta metodológica comprende tres momen- 


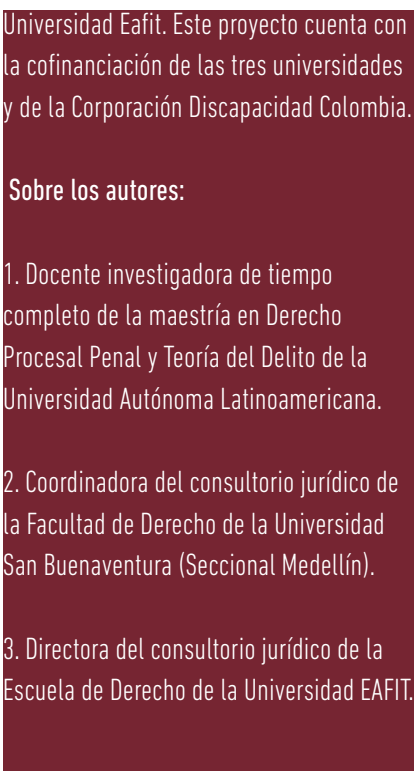

tos: Exploratorio, focalización y profundización. El problema abordado en el proyecto de investigación plantea la necesidad de establecer desde el punto de vista técnico y académico, cómo se garantiza el pleno ejercicio de la capacidad jurídica de las personas con discapacidad mental o discapacidad cognitiva en los procesos civiles, de familia, penal, laboral y de seguridad social. Por lo tanto, la pregunta de investigación que hemos venido buscando responder es la siguiente ¿cómo garantizar la concreción del reconocimiento de la capacidad jurídica de las personas con discapacidad cognitiva o mental en los procesos civil, familia, penal, laboral y seguridad social?

Conforme con los resultados obtenidos hasta ahora en el proyecto de investigación, con este artículo pretendemos analizar los retos normativos que tiene para Colombia la aplicación de la Convención sobre los Derechos de las Personas con Discapacidad (en adelante CDPD) desde el contexto civil y de familia, derecho penal, laboral y seguridad social. Sin embargo, previo a ello consideramos importante hacer una breve referencia al concepto de capacidad jurídica y su dimensión con relación al acceso a la administración de justicia.

La personalidad jurídica es valorada como un derecho fundamental del que goza cualquier persona como titular de relaciones jurídicas y centro de imputación jurídica, esta se compone de algunos atributos como el estado civil, el nombre, la nacionalidad, la capacidad, el patrimonio y el domicilio (Sentencia C 182 de 2016). De esto se desprende que la capacidad como atributo de la personalidad debe ser considerada como un derecho fundamental que se concede a todo ser humano desde su nacimiento hasta su muerte.

La capacidad jurídica es considerada como la facultad que tienen las personas de ser titulares de derechos (Gómez et al, 2004); por lo tanto, esta adquiere una doble dimensión a partir de la capacidad de goce y de la capacidad de ejercicio, la primera considerada como la aptitud para ser titular de derechos y obligaciones, la segunda como la posibilidad que tiene el sujeto de ejercer los derechos, cumplir con las obligaciones y comparecer en juicio por derecho propio (González, 2010).

En términos generales, la capacidad jurídica tiene la característica de ser inherente a todo ser humano, por lo tanto debe ser materializada en todos los ámbitos de la vida de las personas, uno de estos, justamente es el acceso a la justicia que "se relaciona con la posibilidad de los individuos, en igualdad de condiciones, de reclamar y hacer valer sus derechos y eliminar cualquier situación de desigualdad, discriminación, violencia, maltrato o abuso que estén sufriendo" (Cisternas et al, 2013, p. 14). Así las cosas, tanto la capacidad jurídica, como el acceso a la justica son derechos intransferibles de cualquier persona con independencia de su condición.

Para que las personas con discapacidad puedan disfrutar de un verdadero acceso a la justicia y ser beneficiarios de un debido proceso legal en condiciones de igualdad con quienes no afrontan esas desventajas, el proceso debe reconocer y resolver los factores de desigualdad real, por lo tanto, esto obliga a los Estados a adoptar medidas de compensación que contribuyan a reducir o eliminar los obstáculos y deficiencias que impidan o reduzcan la defensa eficaz de los propios intereses (Cisternas et al, 2013).

Según lo expuesto anteriormente, deberíamos decir que la capacidad jurídica no reporta ningún inconveniente conceptual si entendemos que esta hace parte del 
reconocimiento de la personalidad y es intrínseca al sujeto desde su nacimiento. Sin embargo, la clasificación de la capacidad como de goce y de ejercicio, ha generado dificultades en su comprensión sobre todo respecto de esta última cuando se trata de personas con discapacidad.

Durante muchos años y atendiendo a un sistema paternalista a través del cual se descalifica la capacidad de tomar decisiones de manera libre, voluntaria y espontánea de las personas con discapacidad, la capacidad de ejercicio les ha sido negada por la sociedad y por la ley. De acuerdo con Valdés:

La capacidad de ejercicio es la que da lugar a mayores conflictos en la práctica y la que produce más enconadas discusiones doctrinales justamente porque no se ha reconocido por igual a todas las personas, por el solo hecho de ser tales, sino que ha sido vinculada a ciertos requisitos intrínsecos al individuo que marcan, jurídicamente, su posibilidad de válida y eficaz actuación en relaciones jurídicas concretas, específicas, determinadas (Valdés, 2010, p. 41).

Hasta hace pocos años, la capacidad de ejercicio era un derecho vedado para las personas con discapacidad, pues pese a ser titulares de derechos y obligaciones, se les limitaba la posibilidad de ejercicio por cuenta propia, implicándoles vivir bajo el yugo de un modelo asistencialista que limitaba su autonomía y capacidad de decisión sobre los asuntos que afectaban su proceso de vida, quedando relegado el ejercicio de este derecho fundamental a terceros quienes tomaban las decisiones por ellos.

La CDPD impone a los Estados, entre otras cosas, la obligación de garantizar el ejercicio de la capacidad jurídica de las personas con discapacidad, y por ende, acceder a la administración de justicia sin ningún tipo de limitación, teniendo estos la posibilidad acudir y tomar decisiones dentro de los procesos judiciales de manera libre y espontánea, así como de celebrar actos jurídicos por fuera de este. No obstante, pese a que Colombia desde el año 2011 ratificó la CDPD, está en mora de definir legislativamente los compromisos asumidos con relación al reconocimiento de la capacidad jurídica abarcando en sus disposiciones normativas la posibilidad que en adelante tendrán las personas con discapacidad para acudir al sistema judicial y celebrar negocios jurídicos por cuenta propia.

En lo que sigue veremos algunos ejemplos de las implicaciones jurídicas y los retos que debe asumir Colombia para darle aplicación a la CDPD a partir de la normatividad civil, de familia, penal, laboral y seguridad social, que aunque no son las únicos ordenamientos jurídicos que resultan impactados con la aplicación de la convención, hemos decidido trabajar a partir de estos por constituir el objeto de estudio de la investigación.

Aspectos generales de la Convención Internacional sobre los Derechos de las Personas con Discapacidad en el contexto colombiano.

La CDPD aprobada por la Asamblea General de las Naciones Unidas en el año 2006 y ratificada por Colombia en el 2011, compromete a los Estados a tomar las medidas necesarias para asegurar el reconocimiento a la igualdad de derechos y oportunidades de las personas con discapacidad. Así entonces, la CDPD ha permitido que se haga tránsito de un modelo médico asistencialista a un modelo social para las personas con discapacidad. La convención constituye el logro jurídico y político más 
importante a nivel internacional para la población con discapacidad, porque supera el enfoque de la salud, para abordar la discapacidad desde el enfoque de derechos. La discapacidad entendida desde los derechos, implica dejar de considerar la persona con discapacidad como objeto de medidas asistenciales, de beneficencia o caridad y reconoce su condición de sujeto de derechos (Seoane, 2011). La CDPD recoge las luchas y los cambios paradigmáticos que han experimentado en años recientes las personas con discapacidad, en este se les concibe como un sujeto multidimensional al cual deben garantizársele sus derechos humanos en términos de igualdad e inclusión social (Montoya, 2009)

Con la Convención se acepta el reconocimiento creciente de justicia social, igualdad de derechos, equidad, aceptación, pertenencia e inclusión, lo cual releja la perspectiva que todos los seres humanos deben ser valorados y aceptados, vistos como seres únicos, con soportes y equiparación de oportunidades, que participan activamente en las comunidades. Estos principios que se han convertido en el fundamento filosófico de la inclusión, provienen del enfoque de derechos (Seoane, 2011).

Colombia aprueba la Convención en el año 2009 expidiendo la Ley 1346, luego esta es ratificada en el año 2011. Frente a la obligación que asume el país al ratificar la Convención en el año 2013 se promulga la ley Estatutaria 1618, que regula derechos fundamentales e integra el bloque de Constitucional. Esta ley es un logro importante en el país para las personas con discapacidad, toda vez que ha existido un marco normativo amplio, pero que al tratarse de leyes ordinarias no fueron suficientes para proteger y garantizar los derechos de las personas con discapacidad.

De igual manera, la Corte Constitucional reconoce el modelo social de derechos y acepta la inclusión de la Convención como parte del bloque de constitucionalidad. La jurisprudencia Constitucional (Sentencia C- 182 de 2016; Sentencia T-740 de 2014), da por superado el reconocimiento de la capacidad de goce de todas las personas sin excepción, pero limita la capacidad de ejercicio solo a aquellos que cuentan con la voluntad reflexiva que les permita conocer y entender el acto jurídico que pretenden realizar y legitima el proceso de interdicción como un mecanismo eficaz para revestir de eficacia el negocio jurídico.

Se encuentra entonces, una tensión o ruptura entre los lineamientos de la Convención de Naciones Unidas y la posición interna. Por ello, es urgente y necesario adoptar todos aquellos cambios normativos que permitan poner a Colombia acorde con las exigencias de la Convención de Naciones Unidas. El artículo 12 de la CDPD consagra para las personas con discapacidad el igual reconocimiento como persona ante la ley. Este artículo es tal vez el instrumento más grande y presenta el mayor rol prescriptivo de normas con aplicación objetiva e inmediata, convirtiéndose en una obligación para los Estados que la ratificaron de modificar la legislación interna de todas las normas que sean contraria a la Convención, de tal manera que deberán modificar, entre otras, las leyes civiles, familiares, contractuales, penales, laborales y de seguridad social, tal y como veremos a continuación.

\section{Efectos de la Convención en la normatividad civil y de familia}

Tal y como se mencionó anteriormente, el concepto de capacidad de ejercicio está fuertemente vinculado al principio de autonomía de la voluntad, conforme al cual se reconoce a los particulares la potestad de regular sus propias relaciones jurídicas, al crear la regla de derecho de obligatorio cumplimiento para las partes involucradas en el negocio jurídico. Sin embargo, las consecuencias que se derivan del concepto 
de capacidad de ejercicio, alude más al concepto de validez de la norma jurídica, que tanto preocupa al derecho. Como se verá, la capacidad legal de las personas con discapacidad mental absoluta, es un tema que genera fuertes controversias, ya que actualmente el acto o negocio jurídico no produce efectos cuando una de las partes tiene esta condición.

Adicionalmente, otro de los aspectos que ha generado mayor debate jurídico es aquel relacionado con los derechos sexuales, reproductivos, a conformar una familia, a contraer matrimonio, una unión marital de hecho y a tener hijos de las personas con discapacidad.

Por lo tanto, a continuación veremos cómo se abordan estás dos temáticas en el contexto colombiano.

\section{El problema de la validez de la norma jurídica en el acto jurídico}

En Colombia se relaciona el concepto de capacidad con el concepto de validez de la norma jurídica. Esto quiere decir que para que un negocio jurídico produzca plenos efectos, requiere que el titular del mismo cuente con la madurez reflexiva para entender y comprender el acto en sí y el alcance de su decisión, de lo contrario la regla particular carece de efectos jurídicos, pues la sanción legal es la denominada nulidad absoluta del negocio jurídico. Por consiguiente, el Código Civil continúa asociando el concepto de discapacidad mental con el concepto de incapacidad legal. Es así, como el artículo 1504 del Código Civil, señala que los dementes, hoy persona con discapacidad mental (Ley 1306 de 2010), y sordomudos (sic) son incapaces absolutos y sus actos no producen ni siquiera obligaciones naturales. Tradicionalmente se ha afirmado que la finalidad de la norma es proteger la integridad del patrimonio de este grupo de personas, pero en la práctica esta posición conlleva el desconocimiento de los lineamientos de la CDPD que reclama el pleno uso y ejercicio de todos los derechos sin restricción, sin que para tales efectos importe la condición personal del sujeto.

Para el legislador Colombiano resulta más importante la validez del derecho, que el reconocimiento del principio de dignidad humana y de autonomía de la voluntad, pues continua sin propiciar los cambios normativos que se requieren implementar conforme al modelo social que se reconoce en la CDPD a partir del cual y bajo la perspectiva del enfoque de derechos, corresponde al Estado y a la sociedad eliminar las barreras y realizar los ajustes necesarios para garantizar a todas las personas la capacidad de auto determinarse.

Hasta el momento, la solución que ofrece la legislación colombiana para revestir de validez la norma jurídica en la que uno de los titulares de la relación jurídica es una persona con discapacidad mental absoluta, es el proceso de interdicción, mediante el cual un tercero que designa el juez se encuentra facultado para obrar en nombre y representación del "incapaz absoluto" como se le denomina en la Ley 1306 de 2009. En ejercicio del rol de curador o consejero, el tercero sustituye la voluntad del titular del acto jurídico, lo que contraría, el principio universal de la dignidad humana.

Por lo anterior, para lograr una evolución de la normatividad colombiana en torno a este tema, se hará necesaria la aplicación de un modelo de apoyo que reconozca y respete la voluntad de la persona con discapacidad, permitiéndole participar efectivamente en la celebración de actos jurídicos. Mediante el modelo de apoyos se permite la participación efectiva del sujeto de la relación jurídica, ofreciéndoles a 
las personas con discapacidad la aplicación de los mecanismos necesarios para que puedan intervenir activamente en las decisiones que deben adoptar como sujetos de derechos y obligaciones.

Corresponde entonces al Estado, al legislador y a la sociedad diseñar aquellos mecanismos que tienen como propósito, brindar herramientas para que la persona con discapacidad, en especial con discapacidad intelectual, pueda tomar sus propias decisiones o para que un tercero, si fuera el caso y de manera excepcional, tome la decisión pero teniendo en cuenta la voluntad y las preferencias del titular del acto jurídico. De esta manera, se migra entonces del sistema sustitutivo de la voluntad a un modelo de apoyo donde el centro siempre será el titular del acto.

\section{Derechos sexuales y reproductivos, el derecho a conformar una familia y a con- traer matrimonio de las personas con discapacidad.}

Tal y como se ha mencionado antes, la CDPD consagra en su artículo 12 el reconocimiento de las personas con discapacidad, como sujetos con total capacidad ante la ley y con igualdad de condiciones en todos los aspectos de su vida. Adicionalmente, en su artículo 17 se refiere al respeto de su integridad física y mental en cualquier momento.

No obstante, en Colombia actualmente existen grandes obstáculos para que las personas en situación de discapacidad puedan ejercer con plenitud derechos sexuales, reproductivos, a conformar una familia y a contraer matrimonio. En este sentido, se hace necesario abordar esta problemática que se puede ver a partir de tres dimensiones principales, la dimensión familiar-social, la dimensión educativa y la dimensión jurisprudencial.

\section{Dimensión Familiar-Social}

Pese a que en la actualidad, grandes campañas educativas han intentado renovar el lenguaje y las expresiones con las que se solía hacer referencia a las personas con discapacidad, tales como "inválidos", "minusválidos", "limitados", "disminuidos", entre otros, que incluso regían como definiciones técnicas en el Código Civil Colombiano y otras leyes (Sentencia C-458 de 2015), el uso de nuevos términos más amigables e inclusivos no ha garantizado un cambio en los imaginarios colectivos respecto a las personas con discapacidad. La construcción social de dichas representaciones hoy continúa teniendo repercusión social respecto a la forma en que la sociedad y el núcleo familiar de las personas con discapacidad perciben su conciencia y libertad de decisión. Este imaginario parte del supuesto que son sujetos asexuados, inconscientes de sus manifestaciones corporales-sexuales y que son vulnerables o totalmente incapaces cuando se trata de la posibilidad de llevar una vida sexual activa, sana y responsable (Restrepo, 2014).

A los Consultorios Jurídicos del país acuden frecuentemente parientes de personas en situación de discapacidad intelectual o cognitiva, solicitando orientación para adelantar en sus hijos o familiares intervenciones quirúrgicas anticonceptivas definitivas sobre los mismos ${ }^{1}$. Por un lado, existe un temor constante, especialmente cuando se habla de niñas y mujeres, respecto a las consecuencias psicológicas que un eventual embarazo pueda acarrearles y ven en la esterilización la única forma de evitarles un posible daño físico y moral. Por otro lado, a los familiares de las personas en situación de discapacidad les preocupa en alto grado el costo económico de un embarazo y un hijo, toda vez que dan por sentado que son ellos quienes asumirán 
la carga económica que se deriva del mismo, y más grave aún, consideran que hay una gran probabilidad que el futuro bebé también nazca con algún tipo de discapacidad y lo asumen como algo negativo e indeseable.

\section{Dimensión educativa}

Según al art. 25 de la Convención es obligación de los Estados implementar programas de salud pública, incluso en el ámbito de la salud sexual y reproductiva a las personas con discapacidad. Bajo el entendido que el derecho a la salud se garantiza, en algunos casos, por medio de programas de educación, no es errado afirmar que existe una necesidad latente de políticas de educación inclusivas respecto a esta problemática. Se deben diseñar programas dirigidos de forma directa a las personas titulares de los derechos, y de forma accesoria a sus familiares y a la sociedad en general. Resulta mucho más viable y garantista promover y establecer mecanismos que les permitan decidir de manera autónoma e informada respecto a su futuro, frente a cualquier decisión que quieran adoptar (Art. 25 de la CDPD).

En Colombia es responsabilidad del Estado por medio de sus distintas instituciones garantizar acceso a la educación sexual y reproductiva a las personas con discapacidad, en este sentido se deben establecer grupos de apoyo que velen por el cumplimiento de estos derechos, asegurando condiciones de accesibilidad e inclusión en los mismos. De esta forma, son los Colegios, las Universidades, las Entidades Prestadoras de Salud, entre otros organismos, los llamados a desarrollar herramientas de educación diseñadas de forma especial para todas las personas con discapacidad en sus diversas condiciones.

Adicionalmente, en materia de educación sexual, es de vital importancia informar a las familias que existen otros métodos anticonceptivos no invasivos, ni definitivos para evitar un embarazo no deseado, alternativas que no impiden a la persona titular del derecho conformar un núcleo familiar conforme a sus anhelos y decisiones en el futuro.

\section{Dimensión jurisprudencial}

A falta de una normatividad clara y eficiente respecto a los derechos de las personas con discapacidad, en Colombia ha sido la Corte Constitucional quien ha elaborado un marco jurídico de carácter jurisprudencial en esta materia. Entre otros pronunciamientos que venían formando una línea jurisprudencial, en la sentencia C-131 de $2014^{2}$ la Corte estableció la posibilidad de realizar cirugías de anticoncepción quirúrgica definitivas en personas con discapacidad bajo una serie de estrictos condicionamientos, al considerar que existía un evidente riesgo de detrimento de la dignidad e integridad de las personas en situación de discapacidad, salvo en dos casos:

(i) Cuando exista un riesgo inminente de muerte de la madre a raíz del embarazo certificada por los médicos y autorizada por el menor, previa autorización judicial; (ii) cuando se trate de una discapacidad profunda severa, certificada médicamente, que le impida al paciente consentir en el futuro, de modo que en estos casos deberá solicitarse autorización.

2 Mediante acción pública de inconstitucionalidad, se demandó el artículo $7^{\circ}$ de la Ley 1412 de 2010 , que consagra, entre otras disposiciones la prohibición de prácticas de anticoncepción quirúrgica en menores de edad. Los demandantes, en lo relativo a la situación de las personas con discapacidad reclamaban que éstas "tienen derecho a gozar de una calidad de vida plena y se les deben garantizar sus derechos sexuales y reproductivos. En estos casos, es más que necesario permitir la anticoncepción quirúrgica, puesto que estas personas pueden llegar a ignorar las consecuencias del acto sexual para ellas mismas, sus familias y para el nasciturus." Sentencia C-131-2014. M.P. Mauricio González Cuervo, p. 10. 
Recientemente y en igual sentido, en la sentencia C-182 de 2016, la Corte declaró exequible el artículo 6 de la ley 1412 de 2010 y ratificó la anticoncepción quirúrgica como remedio excepcional, sujeta a la previa declaración de interdicción y a la autorización judicial en aquellos casos en que la persona no puede expresar su voluntad a pesar de los apoyos que puedan prestársele. En la sentencia referida, la Corte afirmó que la autonomía de la voluntad cuando entra en tensión con otros valores constitucionales, debe ponderarse y esta debe ceder en beneficio de las demás "normas y valores constitucionales involucrados" -principio de beneficencia, permitiendo la sustitución de la voluntad a través del representante legal y del juez. Esta postura representa un evidente retroceso y una clara contradicción con los compromisos asumidos por Colombia en la CDPD.

El núcleo del argumento de quienes reclaman el modelo sustitutivo para anular la voluntad de la persona con discapacidad, siguen obrando con fundamento en una posición paternalista so pretexto de impedir el surgimiento de unos efectos adversos al titular del derecho. El otro argumento, es que debe garantizarse que la persona de manera autónoma comprenda completamente en que consiste la decisión a tomar y pueda reflexionar sobre sus consecuencias, de lo contrario un tercero deberá decidir por él.

Tal y como lo anunciamos antes, esta posición de la Corte bajo el concepto de discapacidad de la CDPD conduce al desconocimiento de los derechos de las personas con discapacidad, al adoptar una medida radical en aras de proteger al titular del acto jurídico, especialmente contraria el art. 23 de la Convención, según el cual los Estados partes deberán respetar: "el derecho de las personas con discapacidad a decidir libremente y de manera responsable el número de hijos que quieren tener y el tiempo que debe transcurrir entre un nacimiento y otro, y a tener acceso a información, educación sobre reproducción y planificación apropiados para su edad, y se ofrezcan los medios necesarios que les permitan ejercer esos derechos". Igualmente, se deja de lado la Recomendación General número 24 -artículo 12 de la Convención sobre la eliminación de todas formas de discriminación contra la mujer (CEDAW), donde se señala que la atención a las mujeres con discapacidad deberá tener como eje central su dignidad y los derechos.

En efecto, la anticoncepción quirúrgica es una solución radical y lesiva de la integridad personal, por ello bajo ningún pretexto, ni circunstancia se puede permitir la sustitución de la voluntad para implementar métodos invasivos, radicales y definitivos en el cuerpo de una persona. Existen otras soluciones menos agresivas que conducen al mismo efecto, esto es, la planificación y, por ello corresponde a la sociedad y al Estado, garantizar los apoyos que una persona con discapacidad requiera para ejercer libremente su sexualidad y para controlar el número de hijos que desee tener o evitarlos, si es ese su deseo (PAllS, 2016).

Evidentemente la mayor limitante para la garantía de los derechos sexuales, reproductivos y de conformar una familia, es provocada por los operadores judiciales, al exigir la completa capacidad reflexiva y autónoma, por parte del titular del acto jurídico. De esta manera, en lugar de eliminar las barreras como demanda la Convención y el bloque constitucional, se crean otros muros que anulan e invisibilizan los derechos de las personas, olvidándose por el contrario, que corresponde precisamente a quienes administran justicia, eliminar todos aquellos obstáculos y velar porque se preste la asistencia y los apoyos para que las personas con discapacidad cognitiva o mental, puedan adoptar las decisiones que competen a su vida familiar, 
personal, patrimonial, educativa, social, laboral, entre otros. El apoyo significa precisamente privilegiar la voluntad del sujeto de la relación jurídica, pues cualquier decisión deberá basarse en sus preferencias e inclinaciones.

Lo dicho hasta el momento, permite entonces advertir que es necesario que Colombia asuma serios y verdaderos cambios normativos, que tanto en materia civil, como de familia, permita a la persona con discapacidad celebrar actos jurídicos y ejercer sus derechos sexuales, reproductivos y de construcción familiar a través de decisiones que sean tomadas por sí mismos, pero especialmente debe tener presente, que en los casos de personas con discapacidad intelectual o cognitiva, estas decisiones no pueden ser sustituidas a terceros, sino que deben estar respaldadas por un modelo de apoyo que preserve la autonomía y la voluntad del sujeto.

\section{El impacto de la Convención en el Derecho laboral y la Seguridad Social}

El Derecho del trabajo y la seguridad social son derechos reconocidos por su incidencia directa en el ser humano como autónomo dominador y responsable que no tiene, a diferencia de las demás seres y cosas vivientes valor de uso, ni valor de cambio, es decir que se valora desde y a partir de la dignidad humana (Defensoría del pueblo, 2004).

La CDPD en el art. 26 establece (...) "la garantía del derecho a la salud en igualdad de condiciones que los demás"; asimismo en el art. 27 (...) "establece la obligación de los Estados parte de que reconozcan el derecho que tienen las personas con discapacidad de trabajar en igualdad de condiciones que los demás", de igual manera en el art. 28 advierte que (...) "los Estados reconocen el derecho de las personas con discapacidad a un nivel de vida adecuado para ellas y sus familias, lo cual incluye alimentación, vestido vivienda adecuados, asegurar el acceso de las personas con discapacidad a programas de vivienda pública; asegurar el accesos en igualdad de condiciones de las personas con discapacidad a programas y beneficios de jubilación".

De igual manera, la CDPD en el art. 27 regula el derecho al trabajo de las personas con discapacidad, permitiéndoles por lo tanto (...) "trabajar, en igualdad de condiciones con las demás. La Convención prohíbe la discriminación por motivos de discapacidad y garantiza ajustes razonables en todas las fases del trabajo y el empleo, incluidos la selección, la contratación y el empleo, la promoción y las condiciones de trabajo".

El derecho al trabajo de las personas con discapacidad es uno de los derechos que mayor desarrollo ha tenido, sobre todo porque cuenta con uno de los órganos especializados de Naciones Unidas, que es la Organización Internacional del Trabajo (OIT). El programa de discapacidad de la OIT promueve el trabajo digno para los hombres y mujeres con discapacidad y facilita medios para superar los obstáculos que impiden la plena participación de las personas con discapacidad en el mercado laboral (Naciones Unidas, 2001). Este programa está basado en los principios de igualdad de oportunidades, igualdad de trato y no discriminación.

Sin embargo, desde antes de la expedición de la CDPD, Naciones Unidas promulgó las normas uniformes para la igualdad de oportunidades, en esta se instituyó que en materia laboral los Estados deben reconocer como principio que las personas con discapacidad están facultadas para ejercer sus derechos humanos en materia de empleo; por lo tanto, las disposiciones legislativas y reglamentarias no pueden discriminar contra las personas con discapacidad, ni interponer obstáculos a su em- 
pleo. De igual forma, hace un llamado para que los empleadores realicen los ajustes razonables para vincular personas con discapacidad (Naciones Unidas, 1993).

El derecho del trabajo cuenta con principios propios que informan el ordenamiento jurídico, el más importante es el principio intuito personae que implica un derecho personalísimo, tan patrimonial y moral, como el derecho de autor, protegido por las leyes específicas, denominadas "de propiedad intelectual", aunque medie un contrato de trabajo, la impronta principal es la persona humana (Giorlandini y Giorlandini, 2006). De acuerdo con Sontoro (citado por Podetti, 1997) se afirma que la relación contractual del trabajo es la única de carácter patrimonial que implica de modo directo a la persona, la personalidad y la libertad misma del trabajador. Esto hace que la prestación del trabajo sea personalísima. Todo el derecho del trabajo esta característicamente ordenado a la protección de la personalidad humana del trabajador.

Con fundamento en los anteriores principios, la inclusión laboral para personas con discapacidad ha sido reglamentada en Colombia en el art. 25 de la Constitución Política de 1991, en el capítulo de los derechos fundamentales, en el art. 53 se describen los principios mínimos fundamentales del trabajo y en el art. 54 se hace referencia particular a las personas con discapacidad, en tanto se les debe garantizar un trabajo acorde con las condiciones de salud del trabajador. Aunque en este último, se relaciona la discapacidad como enfermedad, un reciente fallo de Constitucionalidad (Sentencia C- 458 del 2015) permite entender esa disposición normativa a partir del enfoque de derechos de acuerdo al contexto social en el que se desarrolla la persona, a su deficiencia y obliga al empleador y al Estado a realizar los ajustes razonables que se requieran para que las personas con discapacidad puedan desempeñar el trabajo.

A diferencia de lo que sucede con la normatividad civil, de familia y como lo veremos en el acápite posterior con relación a la penal, en materia laboral y de seguridad social, existe ya un avance legislativo con relación al reconocimiento de la inclusión e integración social de las personas con discapacidad, de hecho la ley 361 de 1997, es una norma pionera en materia de protección laboral, toda vez que en el art. 26 garantiza la estabilidad en el trabajo de las personas con discapacidad e integra aspectos relacionados con la accesibilidad, la educación, el trabajo y regula incentivos tributarios para las empresas que empleen personas con discapacidad. De igual manera, el art. 13 de la Ley 1306 del 2009 determina que el derecho al trabajo de quienes se encuentran con discapacidad mental incluye la oportunidad de ganarse la vida mediante un contrato de trabajo estable, libremente elegido o aceptado en un mercado, en un entorno laboral inclusivo y accesible.

Para incentivar justamente la promoción y creación de empleos para las personas con discapacidad la ley 1429 de 2010 en el art. 10 y su decreto reglamentario 4910 de 2011, fija un descuento en el impuesto sobre la renta y complementarios de los aportes parafiscales y otras contribuciones de nómina para los empleadores que contraten personas con discapacidad, regulación que fue reiterada en la Ley Estatutaria 1618 de 2013, art. 13 a través del cual ordena que el Gobierno deberá reglamentar una puntuación adicional en los procesos de contratación pública y concurso de méritos para las empresas que en su planta de personal tengan personas con discapacidad contratadas, con todas las garantías legales y para las empresas de personas con discapacidad, familiares y tutores.

Como se describe, existe una amplia regulación que promueve la inclusión laboral de personas con discapacidad, sin que exista impedimento alguno para la celebra- 
ción del contrato laboral. En la actualidad el Gobierno a través de la bolsa pública de empleo promueve la vinculación laboral de personas con discapacidad, incluidas las personas con discapacidad cognitiva y discapacidad mental, para ello a través del SENA y organizaciones sociales preparan a las personas con discapacidad para la vida laboral.

En el derecho laboral colombiano se define la capacidad para contratar, como aquella que tienen las personas que han cumplido 18 años de edad y excepcionalmente para los menores con un requisito adicional (Isaza, 2010). De tal manera que podríamos afirmar que en Colombia existen elementos normativos suficientes que permiten reconocer la capacidad jurídica plena para que las personas con discapacidad mental y cognitiva puedan suscribir un contrato laboral, siempre y cuando no hayan sido declaradas interdictas, pues estas personas no pueden ingresar al mundo laboral precisamente porque un tercero es quien debe suscribir el contrato de trabajo, y como se mencionó anteriormente, el contrato de trabajo es individual e impersonal, por lo tanto, solo puede ser suscrito por el trabajador. Todo lo anterior encuentra sustento normativo en los artículos 12 y 27 de la CDPD y en la observación número 1 emitida en el año 2014 por el Comité de Discapacidad de Naciones Unidas.

Por otra parte, encontramos que en el Sistema General de Seguridad Social en Pensiones, a las personas con discapacidad mental o cognitiva se les restringe la capacidad jurídica para el acceso a prestaciones económicas tales como la pensión de vejez, invalidez o de sobreviviente, la indemnización sustitutiva o la devolución de saldos, toda vez que se exige que estas sean declaradas en interdicción conforme con las normas civiles vigentes. De igual forma en el Sistema de General de Seguridad Social en Salud se limita la capacidad jurídica de las personas con discapacidad particularmente en el hecho de que un tercero es quien suscribe el consentimiento libre e informado desconociendo el derecho a consagrado en la CDPC. Lo anterior, pese a que la ley 100 de 1993 que reglamenta el Sistema General de Seguridad Social Integral no regula, ni impone una carga adicional como la declaratoria de interdicción para garantizar los derechos a las prestaciones económicas y asistenciales del Sistema General de Seguridad Social en Salud y Pensiones.

La declaración de incapacidad de los individuos según el Código Civil Colombiano y los sistemas que adoptan figuras como la sustitución, es utilizada para la defensa legal en materia contractual para declarar la validez o invalidez del negocio jurídico. En materia de seguridad social aun, sin que la propia ley 100 del 93 lo exija, la discapacidad mental o cognitiva impide que la persona pueda dar su consentimiento libre e informado y en materia pensional se le niega la posibilidad de recibir la pensión sea de vejez, invalidez o sobrevivencia sino se ha declarado en interdicción. Esta situación se presenta porque se presume que la persona con discapacidad mental o cognitiva es incapaz jurídicamente o se decide sobre la base de un diagnóstico general de desorden mental. Aplicarla

Al ratificar la Convención sobre los derechos de las personas con discapacidad, Colombia asumió en virtud del derecho internacional la obligación de adoptarla materialmente. La aplicación es el proceso por el cual los Estados partes adoptan medidas para garantizar el ejercicio de todos los derechos contenidos en un tratado dado dentro de su ámbito de competencia. De tal manera, que al negar la capacidad jurídica en materia de salud y pensiones, se está violando el art. 12 de la CDPD que de acuerdo con las directrices dadas por el Comité de Derechos de las personas con Discapacidad de Naciones Unidas, su implementación debe ser inmediata (Naciones Unidas, 2009). 
Para Palacios (2008, p. 444) la capacidad jurídica es un concepto más amplio que lógicamente presupone la capacidad de ser un potencial titular de derechos y obligaciones pero también supone la capacidad de ejercitar esos derechos y asumir esas obligaciones por sí mismos, esto es, sin asistencia o representación de terceros. La toma de decisiones, que junto con los principios de autonomía, dignidad e igualdad y el artículo que recepta el derecho a vivir de forma independiente, plasma el modelo social de discapacidad en un aspecto muy importante de la vida de las personas: como es la de ser partes, al igual que el resto de humanidad, de las decisiones acerca de sus propias vidas.

Lo anterior, nos permite afirmar como las medidas legislativas en Colombia no han sido suficientes para garantizar los derechos reconocidos en la Convención y específicamente el reconocimiento como persona ante la ley; porque las personas con discapacidad cognitiva y discapacidad mental no pueden tomar decisiones que afecten su propia vida debido a que para efectos civiles, familiares, patrimoniales y económicos no cuentan con capacidad para actuar u obrar en nombre propio y por lo tanto sus actos no tienen validez legal. El histórico "interés superior" para proteger y restablecer los derechos de las personas con discapacidad a través de los sistemas de sustitución como una medida proteccionista del patrimonio de las personas con discapacidad, han resultado violatorias de la dignidad humana y del principio del derecho a la autonomía de las personas con discapacidad de tomar sus propias decisiones frente a situaciones que afectan su mínimo vital.

Por lo tanto, en el derecho interno se requiere la adopción de medidas positivas para que en materia de seguridad social se realicen los reconocimientos necesarios para que las personas con discapacidad puedan acceder de manera libre, voluntaria y autónoma a la pensión de vejez, invalidez o de sobreviviente, pero asimismo se desarrollen a través de políticas públicas las normas que les permiten acceder a empleos públicos o privados, de tal manera, que estas no se conviertan en letra muerta del legislador.

\section{El derecho penal y los retos a la luz de la convención}

Tal y como hemos visto hasta el momento, el reconocimiento de la capacidad jurídica de las personas con discapacidad y el ejercicio de su autonomía, tiene un claro impacto para el derecho civil, de familia, laboral y seguridad social, de igual manera, el derecho penal no resulta ajeno a este tipo de consideraciones y, por lo tanto, las disposiciones normativas que componen tanto el derecho penal sustantivo, como el derecho proceso penal y de ejecución de penas y medidas de seguridad, deben ser adaptadas para alcanzar el cumplimiento de las obligaciones de la CDPD.

Tal y como lo señala la Sentencia C-330 de 2013 en Colombia es inexistente una regulación integral legislativa sobre la participación de las personas con discapacidad en el proceso penal, existiendo claros vacíos jurídicos en situaciones donde el imputado debe expresar autónomamente su voluntad como por ejemplo la aceptación de la imputación, el allanamiento, lograr pre-acuerdos con la fiscalía, etc.; asimismo, en el caso de la víctima a la hora de celebrar algún acuerdo conciliatorio, su participación en la declaración testimonial en el juicio o en la audiencia de incidente de reparación. Lo anterior, implica entonces la necesidad de crear un procedimiento y unas políticas adecuadas para la integración de las personas con discapacidad -pero especialmente aquellas con discapacidad intelectual- al proceso penal, con independencia del rol que ejerzan dentro del mismo. Lo anterior significa que la persona con discapacidad puede intervenir dentro del proceso penal como sujeto activo, pasivo o como víctima del delito. 
Las primeras modificaciones que debe enfrentar el legislador tanto en el código penal sustantivo, como en el código procesal penal tienen que ver con el uso de términos que actualmente resultan discriminatorios conforme con las exigencias de la CDPD, pese a lo ya ordenado en la Sentencia que prohíbe usar un lenguaje prejuicioso contra las personas en situación de discapacidad (Sentencia C- 458 del 2015). Al respecto encontramos que el código penal a pesar de referirse en alguno de sus articulados a (Art. 166-3) "persona con discapacidad", también usa indistintamente términos como "persona discapacitada"; (art. 170-1, 179-3. 181-2); "que carezca de capacidad de autodeterminación" (Art.170-1) "condiciones de inferioridad psíquica" (Art. 55 - 9); "discriminación referida a enfermedad o minusvalía de la víctima". Asimismo en el código de procedimiento penal se utilizan términos como "incapaz" (Art. 71, parágrafo art. 92, art. 250, art.522, art. 525) e "incapacidad mental" (Art. 314 numeral 5). Por lo tanto, es preciso que se deroguen estos términos y se adopten aquellos que resulten inclusivos a la luz de la CDPD y de la reciente jurisprudencia.

Por otra parte, cuando el legislador penal se refiere a la persona con discapacidad mental como víctima, indica que este puede acudir al proceso siempre a través de su representante legal, lo que implica entonces que hay un traslado a un tercero de la decisión de conciliar, testificar, intervenir, es decir, que actualmente existe una imposibilidad jurídica para que la persona con discapacidad intelectual que sea víctima de un delito, pueda participar activamente en el proceso dejando cualquier tipo de decisión en manos de terceros.

El acceso a la administración debe garantizarse también a las víctimas de delito sin barrera alguna de acceso, actualmente existen obstáculos que les impiden intervenir directamente en el proceso, generando esta situación que en algunos casos se propicie la impunidad, bien porque se desconocen los recursos legales existentes o bien porque cuando se accede al proceso se genera una victimización secundaria provocada por los funcionarios judiciales (Cuenca \& Berranco, 2014).

Adicionalmente, en un estudio realizado en el año 2014 en España, Cuenca \& Barranco logran advertir como la falta de formación de los funcionarios judiciales, defensores y operadores jurídicos, limitan ostensiblemente el acceso al sistema penal de las personas con discapacidad víctimas de algún comportamiento delictivo:

La escasa formación y especialización de los diversos profesionales del sistema de justicia penal-jueces, fiscales, forenses, abogados, profesionales de las Oficinas judiciales, servicios de apoyo a las víctimas etc. - fomenta, además, la persistencia de prejuicios y estereotipos en relación con las personas con discapacidad intelectual que son percibidas, a menudo, como testigos poco creíbles y escasamente confiables. La prioridad que, según antes se dijo, se concede en nuestro sistema al derecho de defensa provoca que los mecanismos procesales disponibles que podrían usarse para proteger a las víctimas con discapacidad intelectual y favorecer su participación en el proceso penal no se utilicen (videoconferencia, prueba preconstituida). A todo ello se añade el desconocimiento general y las reticencias de los operadores para recurrir en este punto a la Convención Internacional sobre los Derechos de las Personas con Discapacidad (en adelante CDPD) cuya aplicación directa o por vía interpretativa permitiría introducir ajustes razonables y adaptaciones de procedimiento que favorecerían el acceso a la justicia penal de las personas con discapacidad intelectual (Cuenca \& Barranco, 2014, p. 182).

La situación expuesta debe poner a la normatividad penal a tono con la CDPD garantizando a través de reformas normativas la posibilidad que las personas con discapacidad puedan acceder al proceso penal de manera libre y autónoma a través 
del uso de mecanismos de apoyo que le permita acudir al sistema penal y al reconocimiento de todos sus derechos como víctima, avalándole el acceso en todas las fases del proceso penal desde la investigación hasta el juicio. Asimismo, debe haber un compromiso estatal para comenzar a implementar y ejecutar diferentes políticas públicas que promuevan la sensibilización y la capacitación de funcionarios, abogados, servicios de apoyo de las víctimas, etc., para que reconozcan sin prejuicio alguno, la intervención de las víctimas con discapacidad intelectual en el proceso penal.

Lo dicho implica, que la legislación penal -sustancial y adjetiva- deberá enfrentar profundas modificaciones a través de las cuales reconozca a todas las partes e intervinientes la posibilidad de acceder sin ningún tipo de restricción a la jurisdicción penal, sin que se límite su acceso a través de terceros que sustituyan su voluntad, reconociendo la posibilidad de intervención a través de los mecanismos de apoyo que establezca la ley, de tal manera, que estos puedan conocer las actuaciones, formular alegaciones, intervenir en la práctica de pruebas, de igual manera, cuando exista dificultades en la comunicación se les garantice la presencia de un intérprete que de manera idéntica comunique lo que este quiere expresar, para evitar que su testimonio se convierta en un testimonio de oídas.

Por otra parte, la persona con discapacidad intelectual a quien se le haya imputado la comisión de una conducta punible, se le debe definir desde la fase pre-procesal el tipo de mecanismos de apoyo que requiere para que pueda ejercer plenamente su derecho a la defensa y pueda acceder a los beneficios que tiene cualquier persona que se encuentre en conflicto con la ley penal, con independencia de si lo que se busca es la declaratoria o no de la inimputabilidad del sujeto, toda vez que, la finalidad de la sanción penal consistente en la aplicación de una medida de seguridad, no garantiza en absoluto el cumplimiento de los derechos establecidos en la CDPD, en el entendido que para declararse la inimputabilidad habrá que determinarse que el sujeto ha cometido el delito, entre otras cosas, bajo algún trastorno mental que alteró su capacidad de comprender la ilicitud del hecho o determinarse conforme a derecho, pero esto no supone que carezca de la capacidad para comprender lo que sucede al interior del proceso que se adelanta en su contra:

(...) lo determinante para la declaratoria de inimputabilidad no es que el sujeto padezca de algún trastorno mental, sea un inmaduro psicológico o tenga una cosmovisión diferente, sino que ella influya en la comisión de la conducta punible, por lo que puede suceder que un sujeto que se encuentra en alguna de estas condiciones sea condenado a una pena de prisión por cuanto esta no tuvo incidencia en la comisión del hecho punible (ej. Un esquizofrénico que comete lavado de activos) o que una persona sea condenada y una vez esté cumpliendo la pena de prisión sufra de alguna enfermedad mental incompatible con la vida en reclusión formal (Rojas, 2013, p. 24).

Lo anterior implica que pretender la declaratoria de inimputabilidad en un proceso penal no puede generar una limitación para concederle al inimputable los derechos para pre-acordar, negociar o aceptar cargos, como lo hace equívocamente la Corte Suprema de Justicia en algunas de sus decisiones (véase entre otras, Corte Suprema de Justicia, Revisión N³9.565), toda vez que se está partiendo de una presunción iuris et de iure al establecer que como el sujeto no tuvo capacidad para comprender la licitud de la conducta punible, tampoco la tiene para comprender las actuaciones del proceso penal. 
Es preciso que el operador jurídico diferencie dos situaciones, por un lado, la capacidad que tuvo el sujeto al momento de cometer la conducta punible para comprender o no la ilicitud del hecho y que será lo que le permita al juzgador establecer si el sujeto es inimputable o no, pero por otro lado, la capacidad que tienen las personas con discapacidad intelectual de comprender las actuaciones dentro del proceso penal, para esto último tendrán que hacerse las valoraciones correspondientes a través de un médico legista que evalúe la autonomía y la voluntad del sujeto para tomar decisiones en las etapas pre-procesales y procesales, pues la inimputabilidad frente al delito, como se acaba de explicar, no lo hace per se incapaz frente a las actuaciones que se puedan llevar a cabo al interior del proceso judicial.

(...) una cosa es la inimputabilidad del sujeto, referida al momento de la comisión de la conducta punible y, otra distinta, su condición psíquica para asumir un proceso en su contra; de hecho, puede suceder que en este segundo estadio se encuentre plenamente facultado en sus funciones mentales superiores para tomar decisiones de manera consciente y voluntaria, por lo que en este caso no sería necesario adelantar un proceso diferente al de cualquier imputable, con la claridad de que ello en nada incidiría para que en un posible fallo se lo declare como inimputable (Rojas, 2013, p. 25).

Lo anterior, deja entrever como frente a este aspecto, también resulta importante realizar reformas a la ley 906 de 2004 para que las personas con discapacidad intelectual puedan aceptar cargos, celebrar pre-acuerdos y tomar decisiones libres y autónomas en el proceso penal, permitiéndole además hacer uso de los mecanismos de apoyo que sean necesarios para acompañarlos en la toma de su decisión.

Por último, en cuanto a lo que tiene que ver con el sistema penitenciario, hay que decir que en esta materia, si bien las últimas reformas normativas se han orientado a diseñar disposiciones inclusivas para las personas en situación de discapacidad, como se evidencia en la ley 1709 de 2014 -Por medio de la cual se reforman algunos artículos de la ley 65 de 1993, de la ley 599 de 2000, de la ley 55 de 1985 y se dictan otras disposiciones- y en la resolución 5159 de 2015 -Por medio de la cual se adopta el Modelo de Atención en Salud para la población privada de la libertad bajo la custodia y vigilancia del Instituto Nacional Penitenciario y Carcelario INPEC-, las políticas de operatividad de estas normas continúan rezagadas desde su aplicación, entre otras cosas, porque las condiciones reales de las personas con discapacidad en los centros penitenciarios y carcelarios del país resultan contrarías a lo estipulado en estas normas y a lo establecido en la CDPD.

De acuerdo con un informe presentado por el Instituto Nacional Penitenciario y Carcelario (INPEC), a través de la Oficina Asesora de Planeación y el Grupo Estadística en Enero de 2015, el 8.8\% de la población carcelaria correspondía a personas con discapacidad, adicionalmente el $0.5 \%$ son personas que fueron declaradas como inimputables (INPEC, 2015); sin embargo, no existe claridad en el informe, ni en ningún otro, sobre cuáles son las medidas que se vienen adoptando en los centros penitenciarios para garantizar el cumplimiento de la normativa descrita anteriormente, ni las políticas de inclusión social que atienden el tipo de discapacidad que presentan las personas recluidas, tal y como se ha ordenado previamente en algunas decisiones constitucionales (Corte Constitucional T-750A/12).

Para que las condiciones de las personas con discapacidad privadas de la libertad sean tenidas en cuenta desde el momento en el que ingresan al sistema, se sugiere 
que sean valorados por un grupo interdisciplinar a partir del contexto social y personal del que proviene y se pronostique el tipo de discapacidad que presenta. Anticiparse a estas situaciones, permitirá que al condenado se le puedan asignar las medidas de custodia, de apoyo y de reinserción, que garanticen el cumplimiento de sus derechos fundamentales mientras hacen parte del sistema penitenciario.

Una vez se produce el ingreso en prisión de una persona con discapacidad, existen diferentes procedimientos que si bien no están exclusivamente diseñados para ello, pueden contribuir a la detección de los casos. El primero de estos momentos es el proceso de la clasificación interior que se produce tras el ingreso. El interno es entrevistado al menos por un educador, el trabajador social y el servicio médico del Centro. El equipo de tratamiento obtiene y valora la información disponible sobre la situación personal y social del interno (Huete \& Díaz, 2008, p. 106).

Tal y como se ha advertido, en Colombia en lo que tiene que ver con la población que se encuentra privada de la libertad en situación de discapacidad, existen normas y decisiones jurisprudenciales que permitirían pensar que con esto es suficiente para cumplir con las obligaciones asumidas por el Estado colombiano, sin embargo, hasta la fecha no existe una aplicación adecuada de las normas, pues no existen políticas y estrategias administrativas adecuadas para atender a este grupo poblacional, tal y como lo propone el Manual sobre reclusos con necesidades especiales "resulta necesario crear y difundir ampliamente en todos los recintos penitenciarios una declaración de política penitenciaria de servicio que claramente prohíba la discriminación de los reclusos con discapacidad y que promueva ampliamente el tratamiento igualitario" (ONU, 2009, p. 50). De igual manera, se deberá garantizar el acceso a la justicia de las personas con discapacidad que se encuentren privadas de la libertad para que estos puedan realizar sus solicitudes ante el juez de ejecución de penas y medidas de seguridad o autoridades del INPEC contando con los mecanismos de apoyo que les coadyuve al ejercicio autónomo de la voluntad.

En términos generales, vemos como en la legislación penal también se deben asumir profundas y serias modificaciones que permitan contextualizarlas con la CDPD, sin embargo, estas reformas normativas por si solas, no serán suficientes sino existe un compromiso estatal que ponga en marcha políticas públicas que operativicen el ejercicio de la capacidad y la autonomía de la voluntad de los imputados, acusados, procesados, condenados o víctimas en situación de discapacidad que se hallen vinculados por alguna razón al sistema penal o de ejecución penal, pero adicionalmente, esto deberá trascender a un cambio en la mentalidad de los funcionarios y operadores jurídicos para que comprendan los nuevos paradigmas que trae la convención en términos del reconocimiento del derecho a la igualdad.

\section{Conclusión}

Colombia ratificó la Convención en el año 2011, sin embargo son pocos los cambios que se han presentado en la sociedad y menos aún los implementados en la normatividad actual y en las posiciones jurisprudenciales. Se sigue desconociendo el derecho fundamental de auto determinarse, en especial cuando se trata de personas con discapacidad intelectual, lo que se justifica en teorías paternalistas o que devienen de considerar a la discapacidad como una enfermedad. Mientras la sociedad no cambie el imaginario colectivo se seguirán cercenando los derechos y libertades de las personas con discapacidad, pues no se les permitirá decidir libremente como corresponde a cualquier persona, sobre el derecho a conformar una familia, a contraer matrimonio, a tener hijos, a conformar una unión marital, celebrar actos jurídicos, 
acceder a un trabajo digno, adquirir derechos pensionales, participar activamente como víctima o como acusado en el proceso penal, obtener beneficios del sistema penitenciario, entre otros.

En virtud del art. 12 el déficit de capacidad mental, ya sean supuestos o mentales, no deben utilizarse como justificación para negar la capacidad jurídica. Con la consagración de este derecho se debe reevaluar la histórica protección del Estado, regulado bajo el principio del interés superior de la persona con discapacidad cognitiva y mental que sistemáticamente ha puesto en desventaja a las personas con discapacidad. Se debe garantizar es el derecho a la autonomía de la voluntad que implica el reconocer la voluntad y la preferencias de estas personas en la toma de decisiones, esto significa que no se debe sustituir la autonomía de la voluntad a través de los sistemas de sustitución o de interdicción como en el caso de Colombia, por el contrario, el Estado debe proveer un sistema de apoyos para la toma de decisiones en el que prevalezca la voluntad, la presencia y las preferencias de la persona con discapacidad cognitiva y mental.

Se deben por lo tanto, proporcionar los apoyos necesarios para el ejercicio de la capacidad jurídica y este apoyo debe respetar los derechos, la voluntad y la presencia de las personas y nunca debe consistir en decidir por ellas (Naciones Unidas, 2014).

\section{Referencias}

Cisternas, M. et al (2013). Protocolo para el Acceso a la Justicia de las Personas con Discapacidad. Propuestas para un trato adecuado. Madrid: Eurosocial. http:// justiciadiscapacidad.blogspot.com.co/p/presentacion.html

Corte Constitucional. Sentencia T-750A de 2012. Magistrado Ponente: Luis Guillermo Guerrero Pérez, Bogotá. Versión digital disponible en: http://www.corteconstitucional.gov.co/relatoria/2012/T-750A-12.htm. (diciembre de 2016)

Corte Constitucional. Sentencia T- 740 de 2014. Magistrado Ponente: Luis Ernesto Vargas Silva, Bogotá. Versión digital disponible en: http://www.corteconstitucional.gov.co/RELATORIA/2014/T-740-14.htm. (diciembre de 2016)

Corte Constitucional. Sentencia C- 182 de 2016. Magistrado Ponente: Gloria Estella Ortiz Delgado, Bogotá. http://www.corteconstitucional.gov.co/relatoria/2016/c-182-16.htm. (diciembre de 2016)

Corte Constitucional. Sentencia C -131 de 2014. M.P. Mauricio González Cuervo. http:// www.corteconstitucional.gov.co/relatoria/2014/C-313-14.htm. (diciembre de 2016)

Corte Constitucional. Sentencia C-458 de 2015. Magistrado Ponente: Gloria Stella Ortiz Delgado. Versión digital disponible en: http://www.corteconstitucional.gov. co/RELATORIA/2015/C-458-15.htm. (diciembre de 2016)

Corte Suprema de Justicia (2013). Revisión N³9.565. Magistrado Ponente: Gustavo Enrique Malo Fernández. http://www.fiscalia.gov.co/jyp/wp-content/uploads/2015/04/Sentencia-Gian-Carlo-Gutierrez-Suarez-40559-17-abr-2013.pdf

Cuenca, P. \& Barranco, M. (2014). La lucha contra la impunidad del maltrato: el acceso a la justicia penal de las víctimas con discapacidad intelectual. En: I Jornada sobre maltrato a las personas con discapacidad, Sevilla: Universidad Internacional de Andalucía, pp. 181-187. https://dialnet.unirioja.es/servlet/libro?codigo=562353 
Derechos Humanos. Naciones Unidas. Oficina Alto Comisionado (2009.). Informe Comité de los Derechos de las Personas con Discapacidad (Consulta en línea: 18-06-2016 http:/www.ohchr.org).

Defensoría del Pueblo. (2004) ¿Qué son los Derechos Humanos? Bogotá: Red de Promotores de Derechos. http://www.defensoria.gov.co/es/public/contratacion/1465/2004.htm

Giorlandini, E. \& Giorlandini, C. (2006). El Principio de Dignidad Humana. En: Revista del Colegio de Abogados de la Plata (n 67), pp. 65-74.

Gómez, J. et al (2004). Valoración de la capacidad de obrar: el control de los impulsos. Investigación en Salud, vol. VI, núm. 1, abril, pp. 35-42. http://www.redalyc. org/pdf/142/14260107.pdf

Gónzalez, A. (2010) Capacidad jurídica de las personas con discapacidad. México: Comisión Nacional de Derechos Humanos. http://200.33.14.34Var 32.pdf

Huete, A. \& Díaz, E. (2008). Personas con discapacidad afectadas por el sistema penal penitenciario en España. Zerbitzuan (44), pp. 99-114. http://www.cermi.es/ es-ES/ColeccionesCermi/Cermi.es/Lists/Coleccion/Attachments/83/LaspersonascondiscapacidadenelmediopenitenciarioenEspaB1a2.pdf

INPEC et al (2015). Informe Estadístico. Ejemplar 1. Ministerio de Justicia: Bogotá (Consulta en línea: 11-07-2016 http://www.inpec.gov.co/portal/page/portal//npec/Institucion/

Isaza, G. (2010). Derecho Laboral aplicado. Bogotá: Leyer. http://www.edileyer.com/ codigos-anotados/product/871

Montoya, L. (2009). Panorama de la protección jurisprudencial de los derechos humanos de los derechos humanos de las personas con discapacidad en colombia. En: Universitas (n¹18), pp. 115 - 139. http://revistas.javeriana.edu.co/index.php/vnijuri/article/view/14511

Naciones Unidas. (1993.). Normas Uniformes Sobre la Igualdad de Oportunidades para las Persoans con Discapacidad. Nueva York.: Sección de Producción de Naciones Unidas. http://www.who.int/disabilities/policies/standard rules/es/

Organización de las Naciones Unidas (2009). Manual sobre reclusos con necesidades especiales. New York: ONU (Consulta en línea: https://www.unodc.org/documents/justice-and-prison-reform/MANUAL RECLUSOS CON NECESIDADES ESPECIALES 1.pdf

PAIIS (2016). Corte Constitucional viola derecho internacional permitiendo la esterilización forzada de las personas con discapacidad. Bogotá: Universidad de los Andes (Consulta en línea 12-07-2016 http://discapacidadcolombia.com/phocadownloadpap/PUBLICACIONES ARTICULOS/

Palacios, A. (2008) El modelo social de discapacidad: orígenes, caracterización y plasmación en la Convención Internacional sobre los Derechos de las Personas con 
Discapacidad. Madrid: Cermi. http://www.cermi.es/es-ES/ColeccionesCermi/Cermi.es/Lists/Coleccion/Attachments/64/Elmodelosocialdediscapacidad.pdf

Restrepo, I (2014). Derechos sexuales y reproductivos de las personas con discapacidad intelectual: ¿Está preparada nuestra sociedad? Revisado Junio 29, 2016. Universidad del Rosario. Versión digital disponible en: http://www.urosario.edu. co/Universidad-Ciencia-y-Desarrollo/Derechos-sexuales-y-reproductivos.

Rojas, J. (2013). La inimputabilidad y el tratamiento del disminuido psíquico en el proceso penal. Revista de Derecho penal y criminología (97), pp. 43- 67. http:// revistas.uexternado.edu.co/index.php/derpen/article/view/3868

Seoane, J. (2011) ¿Qué es una personas con discapacidad? Ágora-papeles de filosofía (30), pp. 143-161. https://minerva.usc.es/xmlui/handle/10347/7386

Valdés, C. (2010). Capacidad, discapacidad e incapacidad en clave carpenteriana. Revista del Instituto de Ciencias Jurídicas de Puebla (26) pp. 39-68. http://www. redalyc.org/pdf/2932/293222980003.pdf 